\title{
Voltage-Dependent Anion-Selective Channels and Other Mitochondrial Membrane Proteins Form Diverse Complexes in Beetroots Subjected to Flood-Induced Programmed Cell Death
}

\author{
Karla J. Rojas-Méndez ${ }^{1}$, Lino Sánchez Segura ${ }^{2}$, Alicia Chagolla ${ }^{3}$, Bárbara Lino ${ }^{1}$ and \\ Luis E. González de la Vara ${ }^{1 *}$ \\ 'Laboratorio de Bioenergética y Biomembranas, Departamento de Biotecnología y Bioquímica, Unidad Irapuato, Centro \\ de Investigación y de Estudios Avanzados del IPN, Irapuato, Mexico, ${ }^{2}$ Laboratorio de Microscopía, Departamento \\ de Ingeniería Genética, Unidad Irapuato, Centro de Investigación y de Estudios Avanzados del IPN, Irapuato, Mexico, \\ ${ }^{3}$ Laboratorio de Proteómica, Departamento de Biotecnología y Bioquímica, Unidad Irapuato, Centro de Investigación y \\ de Estudios Avanzados del IPN, Irapuato, Mexico
}

OPEN ACCESS

Edited by: Kazimierz Trebacz, Maria Curie-Skłodowska University,

Poland

Reviewed by:

Syed Sifraz Shah,

Forman Christian College, Pakistan

Igor Pottosin,

University of Colima, Mexico

*Correspondence:

Luis E. González de la Vara luis.gonzalezd@cinvestav.mx

Specialty section: This article was submitted to

Plant Physiology,

a section of the journa

Frontiers in Plant Science

Received: 26 May 2021

Accepted: 03 August 2021

Published: 08 September 2021

Citation:

Rojas-Méndez KJ,

Sánchez Segura L, Chagolla A, Lino B and González de la Vara LE (2021)

Voltage-Dependent Anion-Selective Channels and Other Mitochondrial Membrane Proteins Form Diverse Complexes in Beetroots Subjected to Flood-Induced Programmed Cell Death

Front. Plant Sci. 12:714847. doi: 10.3389/fpls.2021.714847
In plants, programmed cell death (PCD) is involved in both the development and the response to biotic and abiotic aggressions. In early stages of PCD, mitochondrial membranes are made permeable by the formation of permeability transition pores, whose protein composition is debated. Cytochrome c (cyt c) is then released from mitochondria, inducing the degradation of chromatin characteristic of PCD. Since flooding stress can produce PCD in several plant species, the first goal of this study was to know if flooding stress could be used to induce PCD in Beta vulgaris roots. To do this, 2-month-old beet plants were flood-stressed from 1 to 5 days, and the alterations indicating PCD in stressed beetroot cells were observed with a confocal fluorescence microscope. As expected, nuclei were deformed, and chromatin was condensed and fragmented in flooded beetroots. In addition, cyt c was released from mitochondria. After assessing that flood stress induced PCD in beetroots, the composition of mitochondrial protein complexes was observed in control and flood-stressed beetroots. Protein complexes from isolated mitochondria were separated by native gel electrophoresis, and their proteins were identified by mass spectrometry. The spectra count of three isoforms of voltage-dependent anion-selective channels (VDACs) increased after 1 day of flooding. In addition, the size of the complexes formed by VDAC was higher in floodstressed beetroots for 1 day ( $200 \mathrm{kDa}$ ) compared with non-stressed ones ( $100 \mathrm{kDa})$. Other proteins, such as chaperonin CPN60-2, also formed complexes with different masses in control and flood-stressed beetroots. Finally, possible interactions of VDAC with other proteins were found performing a cluster analysis. These results indicate that mitochondrial protein complexes formed by VDAC could be involved in the process of PCD in flood-stressed beetroots. Data are available via ProteomeXchange with identifier PXD027781.

Keywords: beetroot (Beta vulgaris), cytochrome c release, flooding stress, mitochondrial membrane protein complexes, programmed cell death (PCD), voltage-dependent anion-selective channels (VDAC) 


\section{INTRODUCTION}

Programmed cell death (PCD) has been reported to be essential for the development of plants (Greenberg, 1996). This process is also implicated in senescence and defense against biotic and abiotic aggressions (Lam et al., 2001). Mitochondria play a dominant role in stress-induced cell death since this phenomenon is initiated when mitochondria perceive death signals via elevated cytoplasmic $\mathrm{Ca}^{2+}$ and reactive oxygen species (ROS) (Petrov et al., 2015). Then, mitochondrial membranes become permeable through the opening of mitochondrial permeability transition pores (MPTPs). The ensuing solute flow through MPTP causes mitochondrial swelling and disruption of the outer mitochondrial membrane (OMM). This allows the release of proteins, such as cytochrome $\mathrm{c}$ (cyt c), from the mitochondrial intermembrane space to the cytoplasm (Van Aken and Van Breusegem, 2015). There, cyt c could initiate a series of reactions ending in massive proteolysis, nucleolysis, and cell disintegration (Dickman et al., 2017).

Among the mitochondrial proteins involved in PCD are voltage-dependent anion-selective channels (VDACs). These proteins are most abundant in the OMM (Takahashi and Tateda, 2013). VDAC is involved in PCD in two ways: first, as the binding site of pro- and antiapoptotic cytoplasmic proteins, and second, as a proposed component of MPTP. Among the antiapoptotic VDAC-binding proteins found in both animals and plants is hexokinase (HK). This enzyme, associated with VDAC, not only catalyzes the phosphorylation of glucose using preferentially the ATP produced by respiring mitochondria (Pedersen, 2008; Alcántar-Aguirre et al., 2013) but also inhibits PCD (Godbole et al., 2013, reviewed in Rodríguez Saavedra et al., 2021). In contrast, it has been proposed that VDAC associates with some mitochondrial inner membrane proteins, such as the adenine nucleotide and/or the phosphate translocators, to form MPTP (Takahashi and Tateda, 2013; Hurst et al., 2017). VDAC oligomerization could also form protein channels through which PCD-initiating proteins could leak out the mitochondria into the cytoplasm (Shoshan-Barmatz et al., 2015, 2018).

Several abiotic stress conditions, such as heat (Balk et al., 1999; Vacca et al., 2004), cold (Koukalová et al., 1997), salt (Wang et al., 2010), or UV radiation (Danon and Gallois, 1998), induced PCD in different plant organs and species (reviewed in Reape and McCabe, 2008; Lord and Gunawardena, 2012). Flooding, one of the most severe types of abiotic stress that causes significant economic losses (Hirabayashi et al., 2013), can also produce PCD in plant cells (Chen et al., 2014; Qi et al., 2018). The immediate consequence of flooding is the decrease in the concentration of available oxygen in the soil. This hypoxia causes extensive alterations in the mitochondrial morphology after few hours of flooding that could lead to either adaptive metabolic changes or irreversible destruction of cell organelles (Vartapetian et al., 2003; Voesenek and Bailey-Serres, 2015). In the roots of some plant species, the death of specific cells causes the formation of aerenchyma, an air-filled tissue that enhances the ventilation of root cells to relieve the hypoxia caused by flooding (Evans, 2003; Voesenek and Bailey-Serres, 2015; Ni et al., 2019). Large changes in the amounts and activities of several mitochondrial proteins have also been observed in flood-stressed plants (Komatsu et al., 2011; Kamal and Komatsu, 2015).

Since Beta vulgaris roots are reported to be sensitive to hypoxia (Petraglia and Poole, 1980), it is conceivable that flooding could be an easy and adequate method to induce PCD in bulky roots similar to them. Then, after observing changes in the cell and nuclear morphology associated with cell death and the leakage of cyt $\mathrm{c}$ from mitochondria in flood-treated beetroots, it was concluded that flood stress could cause PCD in them. Mitochondria from non-stressed and flood-stressed beetroots were then isolated, and their protein complexes were separated by Blue Native gel electrophoresis (Wittig et al., 2006). The proteins in these complexes were identified, and their abundances were estimated, by mass spectrometry. The possible interactions of VDAC with themselves and with other proteins were observed. The results of these observations suggested that VDAC proteins could be involved in PCD induced by flood stress in plants.

\section{MATERIALS AND METHODS}

\section{Biological Material and Flooding Treatment}

Beetroots were grown in a greenhouse under natural conditions as described by Lino et al. (2016). Two months after the seedlings were transplanted to pots, they were subjected to flooding stress by submerging the plant-containing pots in water-filled buckets until the water level reached $3 \mathrm{~cm}$ above the soil surface. Plants were subjected to this treatment for a period of 1-5 days. Control plants were irrigated as needed, allowing adequate drainage of the water.

\section{Preparation, Staining, and Microscopy}

Beetroots were cut into small pieces $\left(\sim 1 \mathrm{~cm}^{3}\right)$, fixed with a $4 \%$ formaldehyde solution for $24 \mathrm{~h}$, and dehydrated with a sucrose solution series (from 10 to $40 \%$ ) for $24 \mathrm{~h}$ in each solution. The samples were sliced manually in thick sections $(\sim 1 \mathrm{~mm})$ and washed with distilled water for $10 \mathrm{~min}$. The sections were stained incubating them in a dilute solution (1:100 from stock) of SynaptoRed ${ }^{\mathrm{TM}} \mathrm{C} 2$ (Sigma-Aldrich, St. Louis, MO, United States) for $1 \mathrm{~h}$ at $4^{\circ} \mathrm{C}$ in darkness. The sections were then washed with distilled water for $15 \mathrm{~min}$, covered with a dilute solution (1:1,000 from a stock) of 4',6-Diamidino-2-phenylindole dihydrochloride (DAPI; Sigma-Aldrich, St. Louis, MO, United States), and incubated for $10 \mathrm{~min}$ at $4^{\circ} \mathrm{C}$ in darkness. These sections were mounted on glass slides, covered with high-performance Zeiss cover glasses, and observed in a multiphoton microscope system (LSM 880-NLO, Zeiss, Oberkochen, Germany) equipped with a Ti:Sapphire laser (Chameleon Vision II, COHERENT, Santa Clara, CA, United States; tuning range: $690-1,060 \mathrm{~nm}$ ). The samples were observed and analyzed with Immersion Objective $40 \times / 1.3$ Oil DIC, NA $\infty / 0.17$, Zeiss Plan NEOFLUAR. DAPI was excited with the chameleon laser tuned at $750 \mathrm{~nm}$ with $0.7 \%$ of power and detected at $403-492 \mathrm{~nm}$. SynaptoRed ${ }^{\mathrm{TM}} \mathrm{C} 2$ was excited with an Argon laser at $514 \mathrm{~nm}$, and the emission from 625 to $750 \mathrm{~nm}$ was recorded. All micrographs were captured in CZI format at 1,131 × 1,131 pixels and RGB color. 
To estimate the size and shape of nuclei, 60 micrographs were captured at $1.5 \mathrm{X}-1.5 \mathrm{Y}$ zoom, equivalent to $8,100 \mu \mathrm{m}^{2}$ of the scanned area. The morphometric analysis of nuclei was carried out with a "cell counter notice" plugin, and the morphometric description was performed by "shape_descriptor1u" in ImageJ version $1.49 \mathrm{p}$ software (National Institutes of Health) as described by Filippi-Chiela et al. (2012).

\section{Preparation of Mitochondria}

Mitochondria were prepared as described by AlcántarAguirre et al. (2013) with modifications. In brief, $120 \mathrm{~g}$ of beetroots were shredded and soaked in $200 \mathrm{ml}$ of a medium containing $300 \mathrm{mM}$ sucrose, $4 \mathrm{mM}$ dithiothreitol (DTT), $3 \mathrm{mM}$ ethylenediaminetetraacetic acid (EDTA), 0.1\% bovine serum albumin (BSA), 0.5\% w/v polyvinylpolypyrrolidone (insoluble PVP), $0.2 \mathrm{mM}$ phenylmethylsulfonyl fluoride (PMSF), and $70 \mathrm{mM}$ Tris- $\mathrm{HCl}$ ( $\mathrm{pH}$ 8.0). This mixture was homogenized for $30 \mathrm{~s}$ with a Braun hand blender. The homogenate was filtered through a fine mesh and centrifuged at $6,000 \times g$ for $20 \mathrm{~min}$. The supernatant was collected and centrifuged at 21,000 $\times g$ for $20 \mathrm{~min}$. The pellets were suspended in a washing medium (0.3 M mannitol, $10 \mathrm{mM}$ 3-morpholinopropane-1-sulfonic acid, potassium salt buffer $\mathrm{pH} 7.4$, and $1 \mathrm{mM}$ EDTA) and centrifuged at $3,000 \times g$ for $20 \mathrm{~min}$; the supernatant was then centrifuged at $21,000 \times g$ for $20 \mathrm{~min}$. The pellet obtained was resuspended in a washing medium, mixed with Percoll to get a concentration of $28 \%(\mathrm{w} / \mathrm{v})$, and centrifuged at $40,000 \times g$ for $1 \mathrm{~h}$ at $4^{\circ} \mathrm{C}$. Mitochondria were collected in the light-brown broad bands near the top of the Percoll gradient formed during the centrifugation. This was mixed with 15 times its volume of washing medium and centrifuged at $12,000 \times g$ for $15 \mathrm{~min}$. The pellets were suspended in a small volume of $25 \mathrm{mM}$ Tris-MES (pH 7.5), 2 mM EDTA, 1 mM DTT, and 45\% (v/v) glycerol and kept at $-70^{\circ} \mathrm{C}$ until use.

\section{Immunodetection of cyt $\mathrm{c}$ and VDAC}

To detect cyt c, samples from either mitochondria or cytoplasm (i.e., the supernatant of the first $21,000 \times g$ centrifugation) were serially diluted. A total of $5 \mu$ l of each dilution were applied to a nitrocellulose membrane, dried, and subjected to immunodetection as described by González de la Vara and Lino Alfaro (2009). The primary antibody used was an antiArabidopsis cyt c antiserum (Agrisera, Vännäs, Sweden). Blots were revealed colorimetrically with 5-bromo-4-chloro-3-indolyl phosphate and nitro blue tetrazolium, as reported by González de la Vara and Medina (1990). In the same way, VDAC relative abundance was estimated in prepared mitochondria using antiArabidopsis VDAC rabbit antibodies (Agrisera, Vännäs, Sweden).

\section{Oxidative Phosphorylation and HK Activity}

The ATP production by respiring mitochondria from control and flood-stressed beetroots was measured in a $0.5-\mathrm{ml}$ enzymatic coupled assay system containing $0.3 \mathrm{M}$ mannitol, $3 \mathrm{mM}$ $\mathrm{MgSO}_{4}, 10 \mathrm{mM} \mathrm{NaCl}, 1 \mathrm{mM}$ glucose, $0.3 \mathrm{mM} \beta$-NADP, $0.07 \mathrm{U} \mathrm{ml}^{-1}$ yeast $\mathrm{HK}, 0.5 \mathrm{U} \mathrm{ml}^{-1}$ of Saccharomyces cerevisiae glucose-6P-dehydrogenase (in $50 \mathrm{mM}$ Tris- $\mathrm{HCl}$ buffer, $\mathrm{pH}$
7.4), $0.1 \%(\mathrm{w} / \mathrm{v})$ fatty-acid-free BSA, $10 \mathrm{mM} \mathrm{Na}$ phosphate, $50 \mathrm{mM}$ Tris-HCl buffer ( $\mathrm{pH}$ 7.4), $0.15 \mathrm{mM}$ ADP, and recently prepared mitochondria. Reactions were started by adding $10 \mathrm{mM}$ potassium succinate. NADP reduction, indicating ATP production, was measured by recording the absorbance at $340 \mathrm{~nm}$ every $15 \mathrm{~s}$ in a Beckman DU-640 spectrophotometer (Brea, CA, United States).

The HK activity was determined in a medium containing $50 \mathrm{mM}$ Tris-HCl buffer ( $\mathrm{pH}$ 7.4), $6 \mathrm{mM} \mathrm{MgCl}_{2}, 1 \mathrm{mM}$ glucose, $1 \mathrm{mM}$ ATP, $0.3 \mathrm{mM} \beta$-NADP, and $1 \mathrm{U} \mathrm{ml}^{-1}$ glucose6P-dehydrogenase (NADP-dependent, from S. cerevisiae). The reaction was started by adding freshly prepared mitochondria. The activity was determined by measuring the NADPH formation through its absorption at $340 \mathrm{~nm}$, using an extinction coefficient of $6.22 \mathrm{mM}^{-1} \mathrm{~cm}^{-1}$.

\section{Native Gel Electrophoresis}

Shredded beetroots were treated with $0.4 \% \mathrm{w} / \mathrm{v}$ formaldehyde (prepared as described in the study by Pertl-Obermeyer et al., 2014 ) in a $20 \mathrm{mM}$ sodium phosphate buffer ( $\mathrm{pH}$ 7.5) for $20 \mathrm{~min}$ to cross-link proteins. Later, $125 \mathrm{mM}$ glycine was added to stop this reaction. Mitochondria were then prepared from these formaldehyde-treated roots as described. However, when this cross-linking step was omitted, very similar results were obtained (data not shown).

Mitochondria were treated with the detergent dodecylmaltoside (DDM) at a detergent/protein ratio of 2 . The separation of membrane protein complexes was performed by Blue Native Polyacrylamide Gel Electrophoresis (BN-PAGE), in $4-13 \%$ polyacrylamide gradient gels, as described by Wittig et al. (2006). Proteins in gels were fixed with 50\% (v/v) methanol and $10 \%(\mathrm{v} / \mathrm{v})$ acetic acid in water and stained with Coomassie Blue (Schägger and von Jagow, 1987). Mitochondrial complexes in a membrane preparation from the chicken heart were used as molecular mass markers (Wittig et al., 2010).

\section{Mass Spectrometry and Data Processing}

Lanes in BN-PAGE gels were sliced as indicated in Figure 6. Proteins in these slices were processed for mass spectrometry as described (Lino et al., 2006), following the method of Shevchenko et al. (1996).

The peptides obtained were analyzed in a linear ion trap LTQ Velos mass spectrometer (Thermo Fisher Scientific, Bremen, Germany) online with a nanoACQUITY (Waters Corp., Milford, MA, United States) liquid chromatography system, with the conditions described by Lino et al. (2016).

The data were analyzed using a Trans-Proteome Pipeline platform (Deutsch et al., 2010), and the results were validated with the PeptideProphet and ProteinProphet software included in this platform. The fragmentation spectra were compared with theoretical ones from a B. vulgaris database (Dohm et al., 2014) obtained from NCBI. Proteins with a ProteinProphet probability $>0.9999$ and, at least, five unique peptides were considered as positively identified. To group the proteins according to their distribution among complexes of different masses, the software NOVA (Giese et al., 2015) was used, choosing the normalization and Pearson's correlation parameters. 


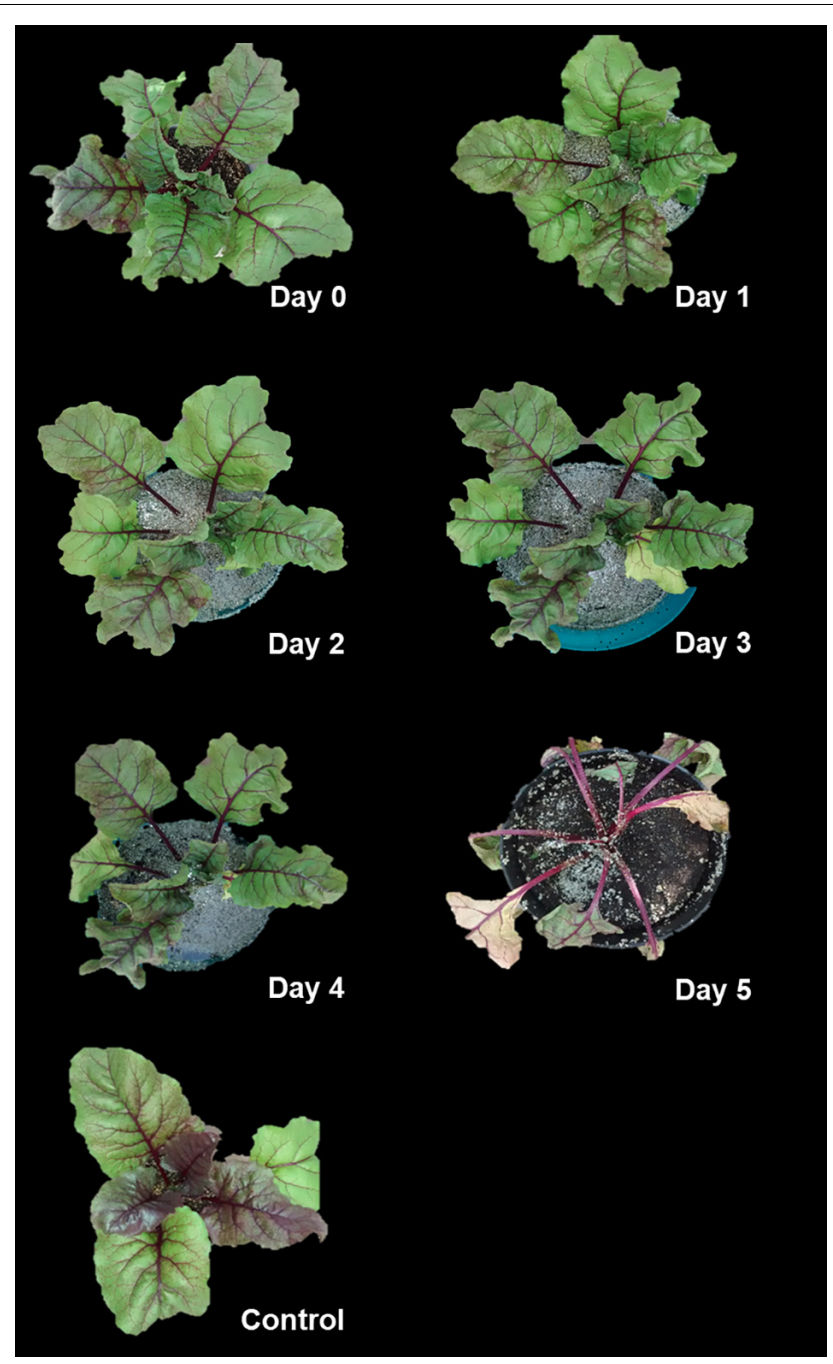

FIGURE 1 | Flooding produces wilting in Beta vulgaris plants. Two-month-old plants were flooded for periods of 1-5 days, as indicated. A control plant, which was irrigated in well-drained soil, is also shown.

\section{RESULTS}

\section{Flooding Produced Morphological Changes Suggestive of PCD in Beetroots}

When 2-month-old B. vulgaris plants were flooded, damages in leaves were apparent in the following few days. They presented several symptoms such as wilting, chlorosis, and vein clearing, especially after 5 days of flooding (Figure 1).

The observations of multiphoton microscopy allowed the recognition of morphological changes in beetroot cells during flooding. The cells of non-flooded roots showed the typical isodiametric shape of parenchyma cells with large central vacuoles and nuclei with near-spherical shapes. These nuclei mostly presented the homogeneously distributed chromatin that is characteristic in non-mitotic cells in mature tissues (Figure 2A). In contrast, after 1 day of flood stress, the cells showed an increase in size, probably due to the accumulation of water in vacuoles. This vacuole enlargement caused the confinement of cytoplasm and nuclei at the periphery of cells. In addition, chromatin condensation produced smaller nuclei (Figure 2B). On the second day of flood stress, the protoplasts of parenchyma cells were detached from cell walls while maintaining the isodiametric shape. Nuclei showed more irregular shapes with wrinkled membranes and fragmentation of chromatin (Figure 2C). On days 3 and 4 of flood stress, chromatin in nuclei appeared more compacted and fragmented (Figures 2D,E). Finally, on the fifth day of flooding, SynaptoRed-stained material was abundant in the cytoplasm, while nuclei showed degraded chromatin and ruptured membranes (Figure 2F and Supplementary Figure 1).

For a quantitative assessment of nuclear alterations, a nuclear morphometric analysis was performed on DAPI-stained nuclei (Supplementary Figure 1), as described by Filippi-Chiela et al. (2012). This method classifies the nuclei according to their size and irregularities, allowing to spot senescent, mitotic, or apoptotic nuclei. This analysis showed that small-regular (SR) nuclei, considered to be apoptotic, were absent in non-flooded beetroots. In contrast, $12.6 \%$ of nuclei were SR after 1 day of flooding, and $43.9 \%$ in beetroots flooded for 5 days (Figure 3).

\section{Oxidative Phosphorylation and HK Activity Decreased in Mitochondria From Flood-Stressed Beetroots}

Mitochondria were prepared from beetroots as indicated in the section "Materials and Methods." To estimate the functional integrity of these mitochondria, the production rate of ATP by oxidative phosphorylation was measured in recently prepared mitochondria from control and floodstressed plants. Compared with mitochondria from control beetroots, oxidative phosphorylation decreased $\sim 20 \%$ after 1 day of flood treatment. A larger decrease was observed in mitochondria from plants stressed for 5 days: the production rate of ATP was less than $50 \%$ of that observed in unstressed mitochondria (Figure 4A).

Hexokinase is located mainly on the OMM, functionally bound to VDAC (Alcántar-Aguirre et al., 2013). Hence, HK activity was measured to estimate the detachment of this enzyme from OMM, or the loss of this membrane, caused by flood stress. HK-specific activity decreased by $\sim 42 \%$ on the first day of flood-stress treatment and by $\sim 45 \%$ on the fifth day (Figure 4B).

\section{Cytochrome c Was Released From Mitochondria During Flood Stress}

During the preparation of mitochondria, the $21,000 \times g$ supernatant was kept and considered to contain cytoplasmic solutes. The cyt $\mathrm{c}$ content of both mitochondria and cytoplasm from control and flood-treated beetroots were estimated by immunodetection (Dot blot) with an anti-Arabidopsis cyt $\mathrm{c}$ antibody. This cytochrome was found in both mitochondria and cytoplasm. The greatest amount of cyt $c$ in the mitochondrial fraction was found in the control sample (Figure $\mathbf{5 A}$, time 0 ). 

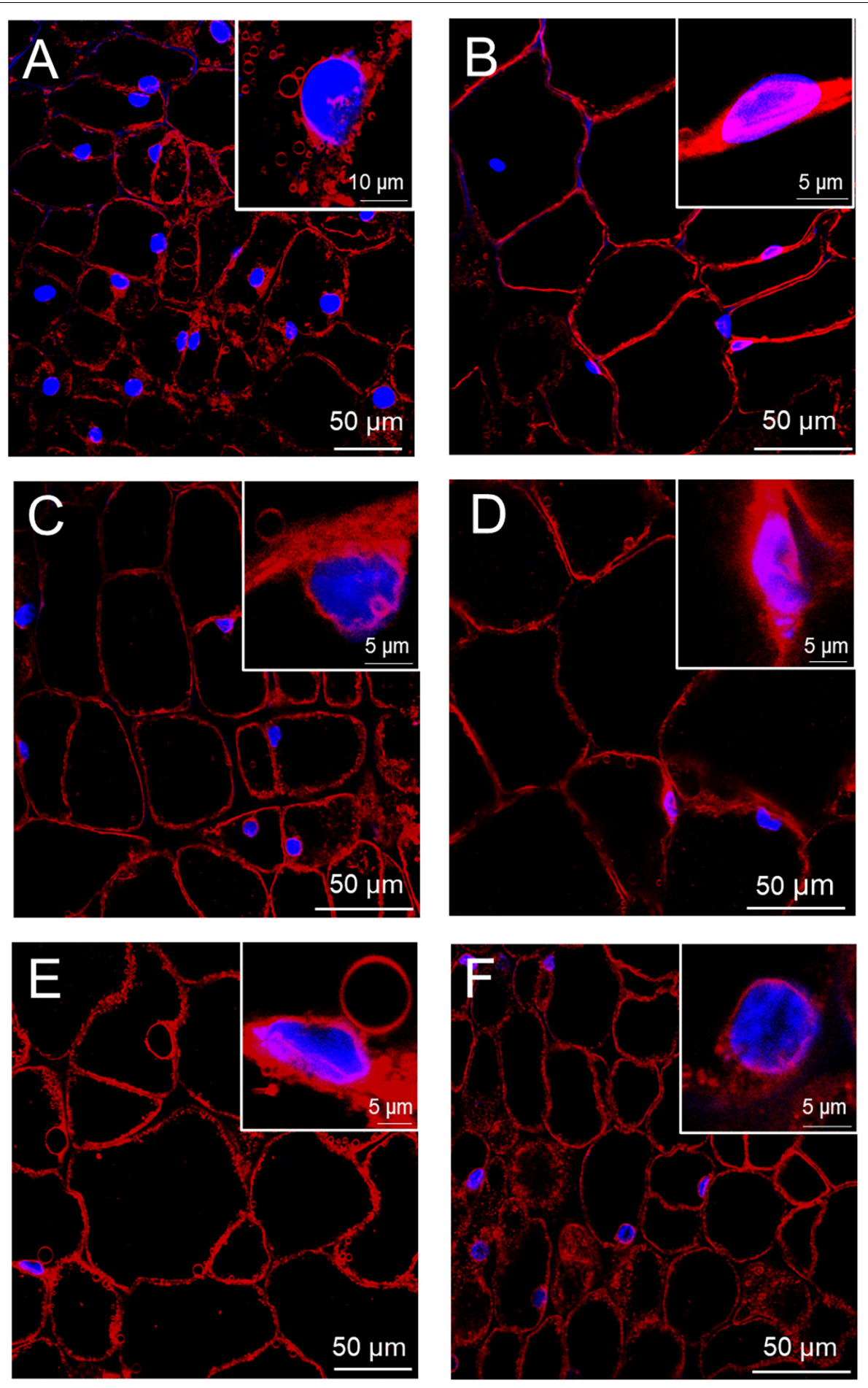

FIGURE 2 | Progressive cell and nuclear damages in beetroots flooded for several days. Thick ( $1 \mathrm{~mm})$ sections were taken from control beetroots (A) or from beetroots flooded for 1 day (B), 2 days (C), 3 days (D), 4 days (E), and 5 days (F). Nuclei were stained with DAPI (blue) and membranes with SynaptoRed ${ }^{T M}$ C2 (red). Confocal microscope images were obtained with a Zeiss multiphoton microscope as described in the section "Materials and Methods." Insets show magnified images of selected nuclei.

This contrasts with the cytoplasmic fraction, where the highest amount of cyt $\mathrm{C}$ was found in beetroots flood-treated for 5 days (Figure 5B, time 5), where this antigen was observed even in the 1:256 dilution. These results indicate that, most probably, cyt $\mathrm{c}$ was released from mitochondria during the flood-stress treatments applied. 


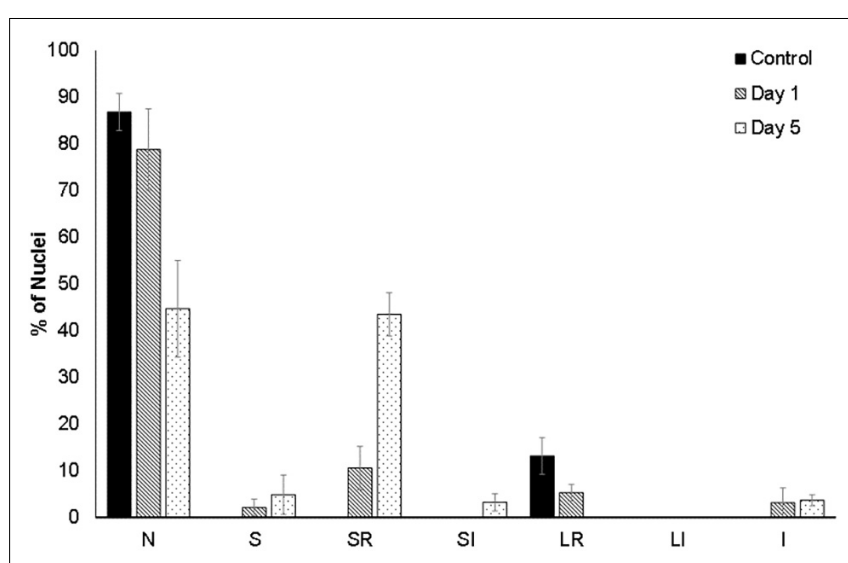

FIGURE 3 | Morphometric analysis of the cell nuclei of beetroots. Using the ImageJ plug-in from the study by Filippi-Chiela et al. (2012), nuclei in cells from control (non-flooded) beetroots and from beetroots flooded for either 1 day or 5 days, were classified according to their size and irregularities as follows: N, normal nuclei; S, small (mitotic); SR, small and regular (apoptotic); $\mathrm{SI}$, small and irregular; LR, large regular (senescent); LI, large irregular; I, irregular. At least, 60 nuclei (observed in several sections of one beetroot) were analyzed for each treatment.

\section{Voltage-Dependent Anion-Selective Channel Abundance Was Higher in Mitochondria From Beetroots Flood-Stressed for 1 Day}

To observe the mitochondrial protein complexes in control and flood-stressed beetroots, mitochondria were treated with the detergent DDM at a detergent/protein ratio of 2 (a ratio previously determined to be optimal). Solubilized protein complexes were then separated by Blue Native electrophoresis (Wittig et al., 2006). After staining the gel, the densitometric traces in Figure 6B were obtained. In them, an increase in the intensity of stained protein bands was observed in sections 48 (corresponding to molecular masses from 700 to $200 \mathrm{kDa}$ ) in response to flood treatment. Later, a lane from each day of treatment was sliced into 10 sections (Figure 6A), and proteins in each section were identified by tandem mass spectrometry (MS/MS).

A total of 76 mitochondrial proteins were identified by MS/MS (Supplementary Table 1). Protein complexes producing most peptide fragmentation spectra were the ATP synthase (Complex V), NADH dehydrogenase (Complex I), and ubiquinol-cytochrome $\mathrm{c}$ oxidoreductase (Complex III). Other abundant proteins (as estimated by their explained spectra count) were the mitochondrial transporters for ADP/ATP, phosphate, and dicarboxylates/tricarboxylates. Chaperonins CPN60-2 and CPN60-like 2 presented $\sim 100$ explained fragmentation spectra in all conditions.

Few proteins produced more peptide spectra when extracted from flood-stressed beetroots. Most noticeably, VDACs produced 2.7 times more peptides after 1 day of flood treatment. After 5 days of flood treatment, VDAC spectra counts returned to $83 \%$ of control levels (Supplementary Table 1). These changes in
VDAC abundance were confirmed immunologically: in Figure 7, the results of a Dot blot experiment are presented. In this study, in almost all dilutions, it is observed that the abundance of immunodetected VDAC was higher in mitochondria from beetroots subjected to flooding for 1 day. After 5 days, VDAC content was lower than that found in control mitochondria. The densitometric analysis of the Dot blot in Figure 7 allowed us to estimate that VDAC content in mitochondria increased 1.9 times when beetroots were flood-stressed for 1 day and decreased to $46 \%$ of control values in beetroots flooded for 5 days (Supplementary Table 2). These results are consistent with those estimated by spectra counting, as shown in Supplementary Table 1.

Not all OMM proteins behaved the same way similar to VDAC. Spectra counts of HK, for instance, decreased by $87 \%$ and $58 \%$ of control values in mitochondria from beetroots flooded for 1 day and 5 days, respectively. These values are comparable with the activity of HK measured in isolated mitochondria (Figure 4B).

\section{Protein Complexes Formed by VDAC Differed in Size in Mitochondria From Control and Flood-Stressed Beetroots}

In addition to their changes in abundance, VDAC proteins showed changes in the size of the complexes they form in beetroots subjected to flooding stress. In mitochondria from control beetroots, three VDAC isoforms mainly form complexes with masses of $\sim 93 \mathrm{kDa}$ (VDAC-2 and $34 \mathrm{kDa}$ VDAC-like) or $\sim 135 \mathrm{kDa}$ (VDAC of $36 \mathrm{kDa}$ ). However, in mitochondria from beetroots flood-stressed for 1 day, these three VDAC isoforms appeared mainly in complexes with a mass of $\sim 202 \mathrm{kDa}$, indicating a possible formation of hexamers or complexes with other proteins. On the fifth day of flooding treatment, VDAC proteins reverted to form complexes with lower masses, i.e., $\sim 93-135 \mathrm{kDa}$ (Supplementary Table 3).

For analyzing the possible associations between mitochondrial proteins, the tool NOVA was used (Giese et al., 2015). With it, the migration profiles of identified proteins were used to perform the hierarchical clustering shown in Supplementary Figure 2. This clustering analysis grouped well the proteins in respiratory chain complexes. For instance, proteins of Complex III were grouped in a $\sim 363 \mathrm{kDa}$ complex in mitochondria from both control and flood-treated beetroots. Other complexes are formed by prohibitin: two isoforms of it were found migrating at more than $1,300 \mathrm{kDa}$, without presenting significant changes with the flood treatments.

The possible interactions of VDAC with other proteins are illustrated in Figure 8. Two proteins appeared forming complexes of the same mass as those formed by VDAC in mitochondria from both control and flood-treated beetroots: the ATPase family AAA domain-containing protein 3B-like and the mitochondrial dicarboxylate/tricarboxylate transporter DTC-like (DTCL). In mitochondria from control beetroots, VDAC-2 and $34 \mathrm{kDa}$ VDAC-like appeared to be associated together and with dihydroorotate dehydrogenase, in addition to the abovementioned proteins. The $36 \mathrm{kDa}$ VDAC is associated 

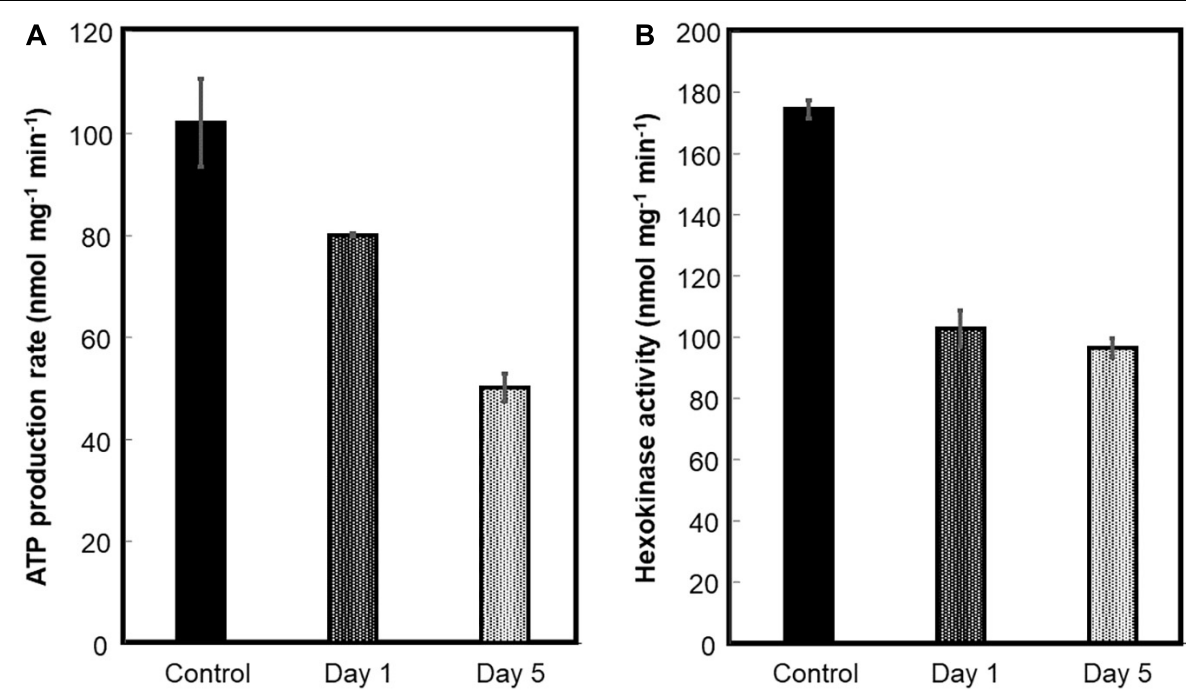

FIGURE 4 | ATP production by oxidative phosphorylation and hexokinase (HK) activity of beetroot mitochondria. Mitochondria were prepared from control and flood-treated beetroots for 1 day or 5 days. The ATP production by oxidative phosphorylation (A) and HK activity (B) was measured as described in the section "Materials and Methods." The data were represented as the mean \pm SD of three experimental determinations.

mainly with the outer envelope pore protein 16-3 and with the glycerol-3-phosphate dehydrogenase SDP6 (Figure 8A). After 1 day of flood stress, the three VDAC isoforms clustered together and with DTCL (Figure 8B). Finally, after the 5-day flood-stress treatment, VDAC (especially $36 \mathrm{kDa} V D A C)$ was found to be associated with $\mathrm{HK}$ in small ( $\sim 93$ to $\sim 135 \mathrm{kDa}$ ) complexes (Figure 8C).

Other proteins presented changes in their complex-size distribution. One was chaperonin CPN60-2, which formed high molecular mass complexes (mainly of $\sim 653 \mathrm{kDa}$ ) under control conditions (Supplementary Figure 2A), while it formed mostly $\sim 286 \mathrm{kDa}$ complexes under flood stress (Supplementary Figures 2B,C). The ADP/ATP carrier protein (XP_010689049.1) is another protein that presented changes in its distribution: it formed medium-sized complexes (mostly of $\sim 286 \mathrm{kDa}$ ) in welldrained beetroots and much heavier $(>1,300 \mathrm{kDa})$ complexes in beetroots flooded for 1 day. Finally, the mitochondrial import receptor subunit TOM40-1-like formed complexes of $\sim 202$ and $\sim 474 \mathrm{kDa}$. These heavier complexes were mostly found in control conditions, while $\sim 202 \mathrm{kDa}$ complexes were enriched in floodstressed beetroots (Supplementary Figure 2).

\section{DISCUSSION}

Beetroot cells are sensitive to anoxia and dependent on mitochondrial respiration for their energy needs (Petraglia and Poole, 1980). The anoxia caused by flooding inhibits growth and produces PCD (Chen et al., 2014; Kamal and Komatsu, 2015; Qi et al., 2018). In the roots of some plant species, the flood-induced PCD causes the formation of aerenchyma ( $\mathrm{Ni}$ et al., 2019). This tissue, formed by air-filled dead cortex cells, enhances the aeration of root cells, facilitating the adaption of the plant to the hypoxia produced by flooding (Evans, 2003;
Voesenek and Bailey-Serres, 2015). To our knowledge, there are no reports of aerenchyma formation in flooded beetroots.

Some structural changes in cellular and subcellular architecture such as chromatin condensation, cell shrinkage, nuclear deformation, and, in mammalian cells, the formation of apoptotic bodies and its subsequent degradation by phagocytosis are considered diagnostic signs of PCD (Lord and Gunawardena, 2012; Dickman et al., 2017). In this study, the nuclear morphological changes were observed in control and flood-stressed beetroot cells by multiphoton fluorescence microscopy. We observed that the nuclei presented a decrease in size and chromatin condensation in cells from beetroots flood-treated for 1 day, while in samples treated for 5 days, many nuclei were completely fragmented (Figure 2). According to the index of nuclear irregularity (Filippi-Chiela et al., 2012), no nuclei deemed as apoptotic were observed in control beetroots. In contrast, almost half of the nuclei analyzed were classified as apoptotic in flood-stressed beetroots (Figure 3).

Another common feature in PCD is the release of cyt $c$ from mitochondria to the cytoplasm, due to the permeabilization of OMM. This release of cyt $c$ has been reported in a variety of organisms, such as yeast, mammals, and plants (Balk et al., 1999; Sun et al., 1999; Martínez-Fábregas et al., 2013), although its role in plant PCD is still under debate (Zhang et al., 2020). In this study, cyt $\mathrm{c}$ was detected in both the mitochondrial and cytosol fractions in control and flood-treated beetroots. However, cyt c content increased in the cytosol after 1 day of flooding. This change was accompanied by a decrease in the amount of cyt $c$ in mitochondria, which suggested cyt c leaked from mitochondria to the cytoplasm. These results, together with the observed nuclear fragmentation, indicated that flooding is an appropriate method to induce PCD in beetroots.

Mitochondria play important roles in responses to stress and plant survival during oxidative stress. When plant mitochondria 


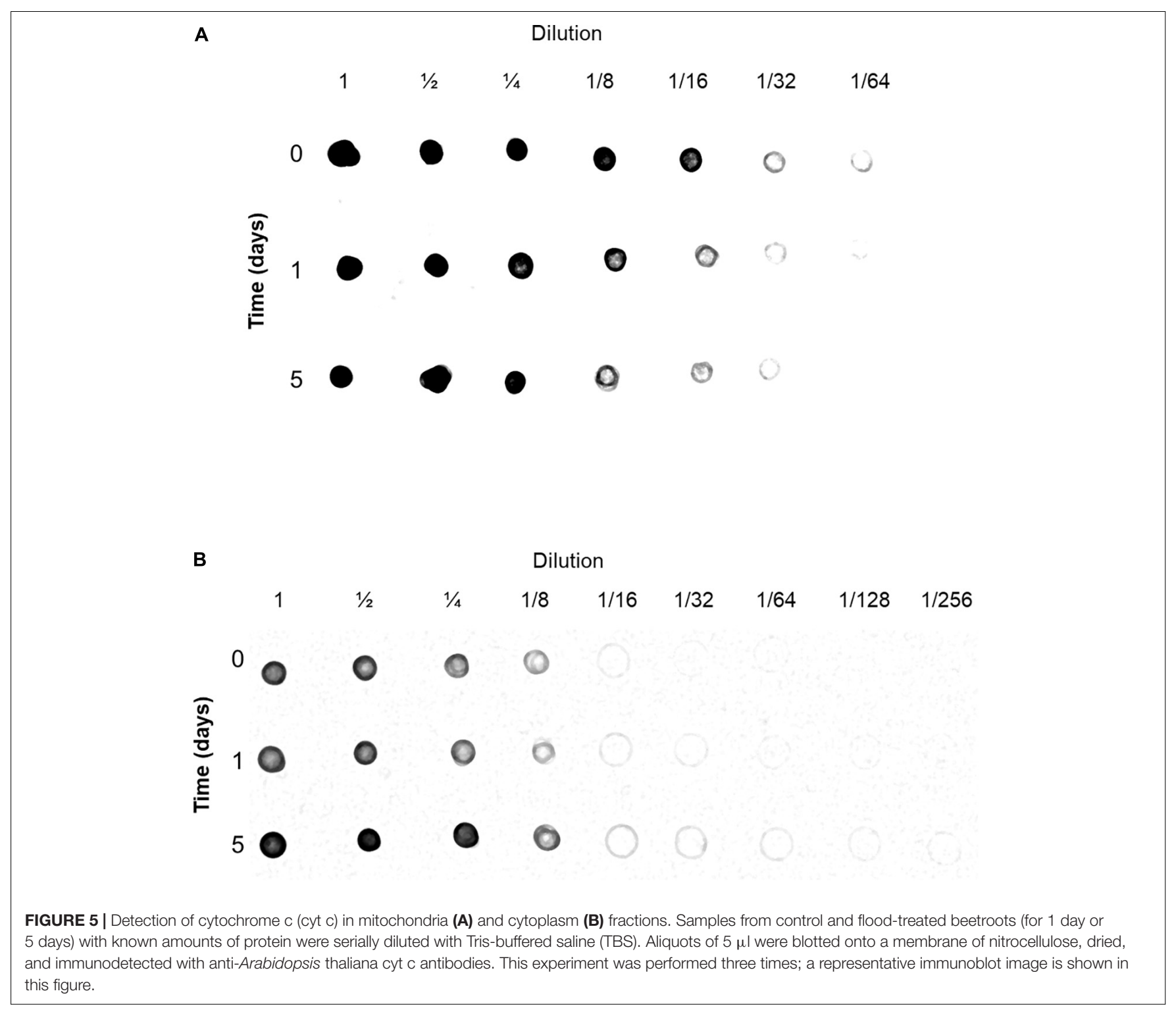

receive $\mathrm{PCD}$-inducing signals (mainly $\mathrm{ROS}$ and $\mathrm{Ca}^{2+}$ ions), the MPTP opens (Van Aken and Van Breusegem, 2015). There is no consensus on the protein components that constitute MPTP. On the one hand, it has been proposed to be formed mainly by VDAC probably bound to inner membrane proteins such as the ADP/ATP carrier or the phosphate mitochondrial translocator (Takahashi and Tateda, 2013; Hurst et al., 2017). On the other hand, it has been proposed that the dimerization of the ATP synthase forms an ion channel through its intramembrane domain (Bernardi et al., 2015).

The BN-PAGE was used in this study to separate protein complexes (Wittig et al., 2006), identifying the proteins in each section of these gels by mass spectrometry (Senkler et al., 2017). This method allowed us to estimate the abundance (by spectra counting) of each identified protein and to detect changes in the masses and the possible composition of mitochondrial protein complexes. Among the proteins that show changes in response to flooding are VDAC isoforms. These OMM channels increase in mitochondria from flooded beetroots (Supplementary Table 1 and Figure 7). This increase has been observed in soybean in response to flooding stress (Komatsu et al., 2011), in elm seeds when PCD was induced by a ROS increase during aging ( $\mathrm{Li}$ et al., 2017), and in PCD induced by ceramide in rice (Zhang et al., 2020). In Arabidopsis, an increase in the VDAC protein Hsr2 was observed after heat- and senescence-induced PCD (Swidzinski et al., 2004). In addition, protein complexes formed by VDAC changed in size with flood stress. In mitochondria from control beetroots, they were found forming mainly trimers or tetramers. However, in mitochondria from beetroots flood-stressed for 1 day, VDAC formed complexes with a mass of $\sim 202 \mathrm{kDa}$, suggestive of hexamers. These different VDAC oligomers have been observed in Arabidopsis (Klodmann et al., 2011; Senkler et al., 2017) and potato OMM (Hoogenboom et al., 2007). The changes in VDAC oligomerization have been associated with the 

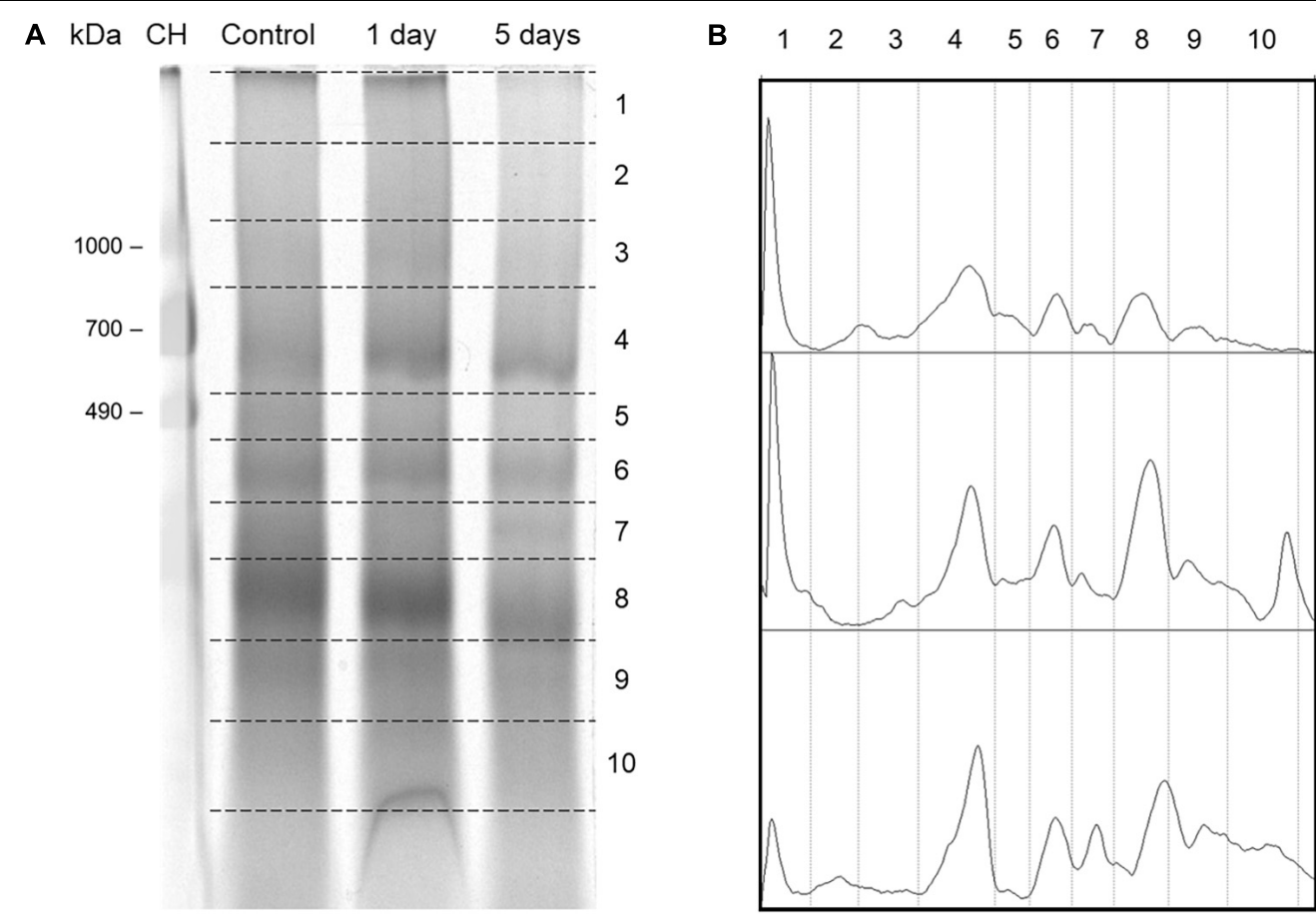

FIGURE 6 | Separation of mitochondrial protein complexes from control and flood-stressed beetroots by Blue Native PAGE (BN-PAGE) for the identification of their proteins by mass spectrometry. (A) A stained BN-PAGE gel image. Mitochondrial protein complexes from control and flood-stressed beetroots for 1 day or 5 days were run in a $4-13 \%$ polyacrylamide gradient gel. Broken lines limit the sections cut for its analysis by mass spectrometry. In the first lane, chicken heart homogenate with $50 \mu \mathrm{g}$ of protein was run as molecular mass markers. Identified mitochondrial proteins are listed in Supplementary Table 1. (B) Densitometric traces of the gel image in (A) were obtained using ImageJ. Calculated mean molecular masses (in kDa) in each gel numbered section were as follows: 2, 1,378; 3, 974; 4, 653; 5, $474 ; 6,363 ; 7,286 ; 8,202 ; 9,135$; and 10, 93. This experiment was replicated three times (one of them omitting formaldehyde during the preparation of mitochondria), obtaining very similar results.

permeabilization of OMM that causes cyt $\mathrm{c}$ release in both animal (Zalk et al., 2005; Shoshan-Barmatz et al., 2008, 2010) and plant cells (reviewed in Takahashi and Tateda, 2013).

In addition to forming oligomers of different sizes, VDAC could associate with other proteins. These associations could change in the process of flood-induced PCD. Among the mitochondrial transporters, the DTCL appeared to form complexes of similar sizes than those formed by VDAC in mitochondria from both control and flood-stressed beetroots. A possible association of DTCL with VDAC has been observed in Arabidopsis (Klodmann et al., 2011). DTCL was induced in the halophyte Suaeda asparagoides under salt stress (Ayarpadikannan et al., 2012), but its possible role in flood-induced PCD is yet to be studied. The ADP/ATP carrier and the mitochondrial phosphate carrier 3, which have been proposed to be the components of different mitochondrial membrane complexes such as the ATP synthase (Pedersen, 2008) and the MPTP (Takahashi and Tateda, 2013), form, accordingly, complexes with very diverse masses.

Hexokinase associates with VDAC, inhibiting apoptosis by preventing the release of cyt $c$ in mammalian mitochondria (Azoulay-Zohar et al., 2004; Abu-Hamad et al., 2008; Shoshan-Barmatz et al., 2008). There is also evidence indicating that $\mathrm{HK}$ bound to VDAC inhibits the formation of MPTP in plant mitochondria (Godbole et al., 2013; Rodríguez Saavedra et al., 2021). A functional association between HK and VDAC has been reported in beetroots, where it was observed that the ATP produced by oxidative phosphorylation in the mitochondrial matrix is preferentially

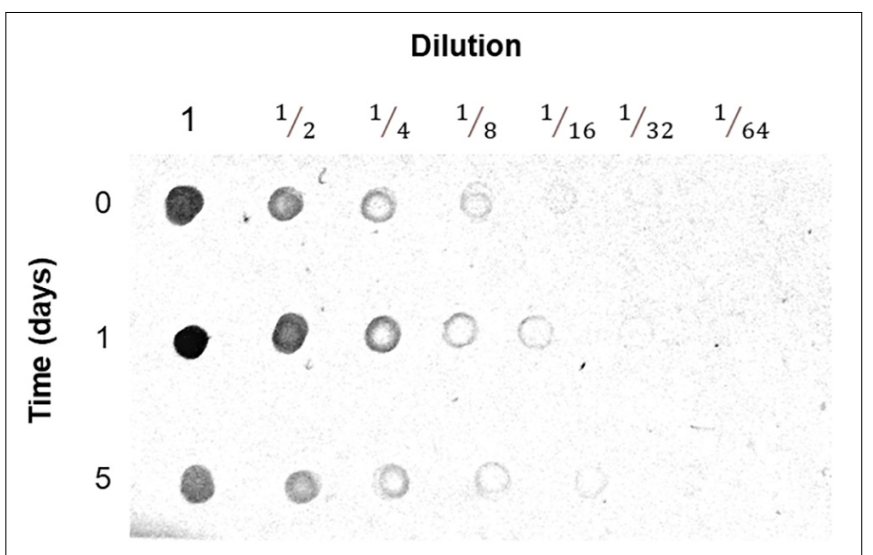

FIGURE 7 | Detection of the voltage-dependent anion-selective channel (VDAC) in mitochondria. Mitochondria prepared from control and flood-treated beetroots (for 1 day or 5 days) with known amounts of protein were serially diluted with TBS. Aliquots of $5 \mu \mathrm{l}$ were blotted onto a nitrocellulose membrane, dried, and immunodetected with anti-VDAC antibodies. In this figure, the results of one of the three experiments performed are presented. 
A

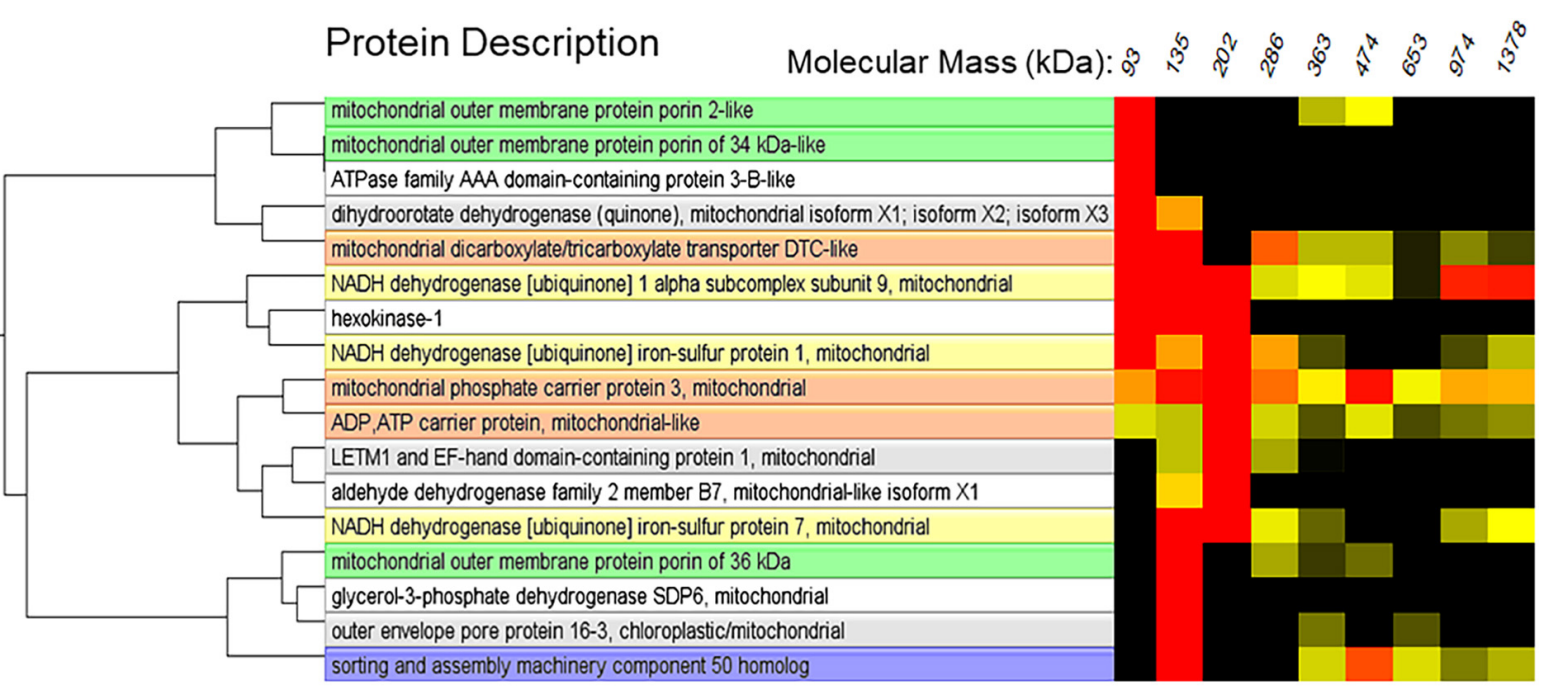

B

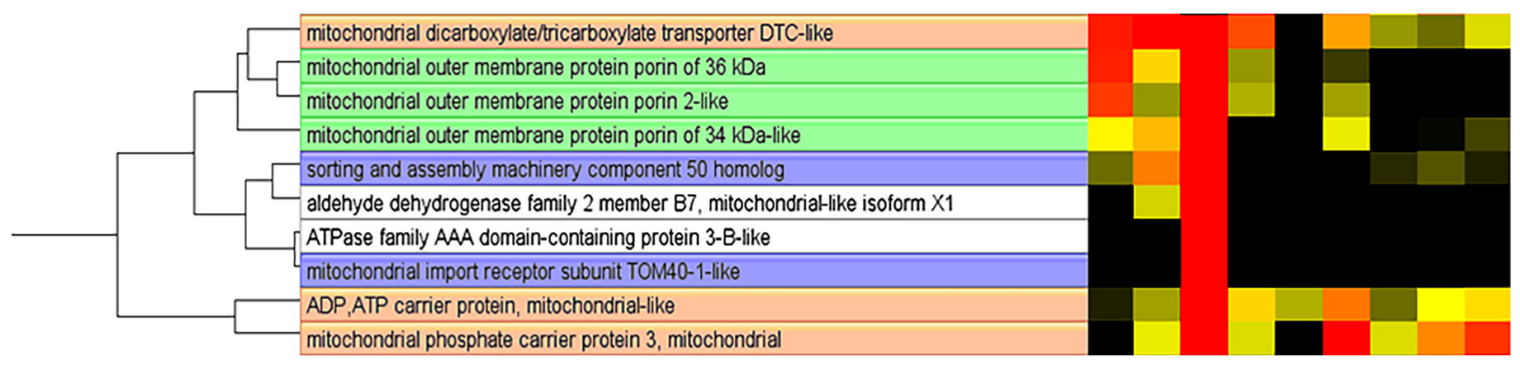

C

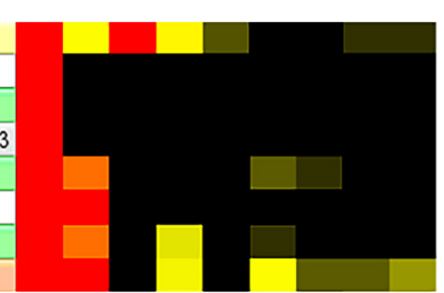

Mitochondrial outer membrane porins

Components for protein assembly (SAM)

Proteins of Complex I

Mitochondrial Transporters

Other Proteins

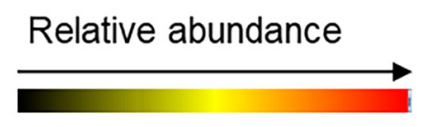

FIGURE 8 | Mitochondrial proteins probably interacting with VDAC in control beetroots (A) or beetroots flooded for 1 day (B) or 5 days (C). The cluster analysis of the proteins separated by the BN-PAGE in Figure $\mathbf{6}$ was performed using the software NOVA. Only the proteins in complexes with a mass distribution similar to that formed by VDAC are shown in this figure. The distribution profiles of all identified mitochondrial proteins are in Supplementary Figure 2.

channeled toward the HK bound to VDAC (Alcántar-Aguirre et al., 2013). In this study, both the activity and the peptide spectra produced by HK decreased in response to flooding stress. HK appeared, in all treatments, in small $(\sim 140 \mathrm{kDa})$ complexes. This mass is consistent with that of an $\mathrm{HK}$ molecule bound to a VDAC trimer.

Finally, the mitochondrial import receptor TOM-40 and the chaperonin CPN60-2 presented changes in the masses of the complexes they form in flood-stressed beetroots. CPN602 increased and formed smaller complexes in flood-stressed beetroots. CPN60-2 protein increased in flood-stressed soybean (Komatsu et al., 2011). Similarly, the mitochondrial chaperonin Hsp60 increased (and was released from mitochondria) after a heat shock in Arabidopsis (Rikhvanov et al., 2007).

\section{CONCLUSION}

The results of this study indicated that flooding stress is a good method to induce PCD in beetroots. Using it, it was observed that 
VDAC, and possibly other proteins, appeared to be involved in the process of PCD induced by flooding stress.

\section{DATA AVAILABILITY STATEMENT}

The data presented in the study are deposited in the ProteomeXchange Consortium via the PRIDE partner repository under accession number: PXD027781.

\section{AUTHOR CONTRIBUTIONS}

KR-M and LG designed this study and wrote the manuscript. KR-M performed most of the research. BL provided technical assistance and advice throughout this study. LS performed the

\section{REFERENCES}

Abu-Hamad, S., Zaid, H., Israelson, A., Nahon, E., and Shoshan-Barmatz, V. (2008). Hexokinase-I protection against apoptotic cell death is mediated via interaction with the voltage-dependent anion channel-1: mapping the site of binding. J. Biol. Chem. 283, 13482-13490. doi: 10.1074/jbc.M708216200

Alcántar-Aguirre, F. C., Chagolla, A., Tiessen, A., Délano, J. P., and González de la Vara, L. E. (2013). ATP produced by oxidative phosphorylation is channeled toward hexokinase bound to mitochondrial porin (VDAC) in beetroots (Beta vulgaris). Planta 237, 1571-1583. doi: 10.1007/s00425-013-1866-4

Ayarpadikannan, S., Chung, E., Cho, C. W., So, H. A., Kim, S. O., and Jeon, J. M. (2012). Exploration for the salt stress tolerance genes from a salt-treated halophyte, Suaeda asparagoides. Plant Cell Rep. 31, 35-48. doi: 10.1007/s00299011-1137-4

Azoulay-Zohar, H., Israelson, A., Abu-Hamad, S., and Shoshan-Barmatz, V. (2004). In self-defence: hexokinase promotes voltage-dependent anion channel closure and prevents mitochondria-mediated apoptotic cell death. Biochem. J. 377, 347-355. doi: 10.1042/BJ20031465

Balk, J., Leaver, C. J., and McCabe, P. F. (1999). Translocation of cytochrome c from the mitochondria to the cytosol occurs during heat-induced programmed cell death in cucumber plants. FEBS Lett. 463, 151-154. doi: 10.1016/s00145793(99)01611-7

Bernardi, P., Rasola, A., Forte, M., and Lippe, G. (2015). The mitochondrial permeability transition pore: channel formation by F-ATP synthase, integration in signal transduction, and role in pathophysiology. Physiol. Rev. 95, 1111-1155. doi: 10.1152/physrev.00001.2015

Chen, Y., Chen, X., Wang, H., Bao, Y., and Zhang, W. (2014). Examination of the leaf proteome during flooding stress and the induction of programmed cell death in maize. Proteome Sci. 12:33. doi: 10.1186/1477-5956-12-33

Danon, A., and Gallois, P. (1998). UV-C radiation induces apoptotic-like changes in Arabidopsis thaliana. FEBS Lett. 437, 131-136. doi: 10.1016/S0014-5793(98) 01208-3

Deutsch, E. W., Mendoza, L., Shteynberg, D., Farrah, T., Lam, H., Tasman, N., et al. (2010). A guided tour of the trans proteomic pipeline. Proteomics 10, 1150-1159. doi: 10.1002/pmic.200900375

Dickman, M., Williams, B., Li, Y., de Figueiredo, P., and Wolpert, T. (2017). Reassessing apoptosis in plants. Nat. Plants 3, 773-779. doi: 10.1038/s41477017-0020-x

Dohm, J. C., Minoche, A. E., Holtgräwe, D., Capella-Gutiérrez, S., Zakrzewski, F., Tafer, H., et al. (2014). The genome of the recently domesticated crop plant sugar beet (Beta vulgaris). Nature 505, 546-549. doi: 10.1038/nature12817

Evans, D. E. (2003). Aerenchyma formation. New Phytol. 161, 35-49. doi: 10.1046/ j.1469-8137.2003.00907.x

Filippi-Chiela, E. C., Oliveira, M. M., Jurkovski, B., Callegari-Jacques, S. M., Silva, V. D., and Lenz, G. (2012). Nuclear Morphometric Analysis (NMA): screening of senescence, apoptosis and nuclear irregularities. PLoS One 7:e42522. doi: 10.1371/journal.pone.0042522 microscopy work. AC provided valuable advice and analyzed proteins by MS. All authors contributed to the article and approved the submitted version.

\section{FUNDING}

KR-M received a doctoral scholarship from CONACYT, Mexico.

\section{SUPPLEMENTARY MATERIAL}

The Supplementary Material for this article can be found online at: https://www.frontiersin.org/articles/10.3389/fpls.2021. 714847/full\#supplementary-material

Giese, H., Ackermann, J., Heide, H., Bleier, L., Drose, S., Wittig, I., et al. (2015). NOVA: a software to analyze complexome profiling data. Bioinformatics 31 , 440-441. doi: 10.1093/bioinformatics/btu623

Godbole, A., Dubey, A. K., Reddy, P. S., Udayakumar, M., and Mathew, M. K. (2013). Mitochondrial VDAC and hexokinase together modulate plant programmed cell death. Protoplasma 250, 875-884. doi: 10.1007/s00709-0120470-y

González de la Vara, L. E., and Lino Alfaro, M. (2009). Separation of membrane proteins according to their hydropathy by serial phase partitioning with Triton X-114. Anal Biochem. 387, 280-286. doi: 10.1016/j.ab.2009.01.035

González de la Vara, L. E., and Medina, G. (1990). Phosphorylation by inorganic phosphate of the plasma membrane $\mathrm{H}^{+}$-ATPase from red beet (Beta vulgaris L.). Plant Physiol. 94, 1522-1527. doi: 10.1104/pp.94.4.1522

Greenberg, J. T. (1996). Programmed cell death: a way of life for plants. Proc. Natl. Acad. Sci. U.S.A. 93, 12094-12097. doi: 10.1073/pnas.93.22.12094

Hirabayashi, Y., Mahendran, R., Koirala, S., Konoshima, L., Yamazaki, D., Watanabe, S., et al. (2013). Global flood risk under climate change. Nat. Clim. Change 3, 816-821. doi: 10.1038/nclimate1911

Hoogenboom, B. W., Suda, K., Engel, A., and Fotiadis, D. (2007). The supramolecular assemblies of voltage-dependent anion channels in the native membrane. J. Mol. Biol. 370, 246-255. doi: 10.1016/j.jmb.2007.04.073

Hurst, S., Hoek, J., and Sheu, S. S. (2017). Mitochondrial $\mathrm{Ca}^{2+}$ and regulation of the permeability transition pore. J. Bioenerg. Biomembr. 49, 27-47. doi: 10.1007/ s10863-016-9672-x

Kamal, A. H. M., and Komatsu, S. (2015). Involvement of reactive oxygen species and mitochondrial proteins in biophoton emission in roots of soybean plants under flooding stress. J. Proteome Res. 14, 2219-2236. doi: 10.1021/acs. jproteome.5b00007

Klodmann, J., Senkler, M., Rode, C., and Braun, H.-P. (2011). Defining the protein complex proteome of plant mitochondria. Plant Physiol. 157, 587-598. doi: 10.1104/pp.111.182352

Komatsu, S., Yamamoto, A., Nakamura, T., Nouri, M. Z., Nanjo, Y., Nishizawa, K., et al. (2011). Comprehensive analysis of mitochondria in roots and hypocotyls of soybean under flooding stress using proteomics and metabolomics techniques. J. Proteome Res. 10, 3993-4004. doi: 10.1021/pr2001918

Koukalová, B., Kovařik, A., Fajkus, J., and Široký, J. (1997). Chromatin fragmentation associated with apoptotic changes in tobacco cells exposed to cold stress. FEBS Lett. 414, 289-292. doi: 10.1016/S0014-5793(97)01008-9

Lam, E., Kato, N., and Lawton, M. (2001). Programmed cell death, mitochondria and the plant hypersensitive response. Nature 411, 848-853. doi: 10.1038/ 35081184

Li, Y., Wang, Y., Xue, H., Pritchard, H. W., and Wang, X. (2017). Changes in the mitochondrial protein profile due to ROS eruption during ageing of elm (Ulmus pumila L.) seeds. Plant Physiol. Biochem. 114, 72-87. doi: 10.1016/j.plaphy.2017. 02.023

Lino, B., Carrillo-Rayas, M. T., Chagolla, A., and González de la Vara, L. E. (2006). Purification and characterization of a calcium-dependent protein kinase from 
beetroot plasma membranes. Planta 225, 255-268. doi: 10.1007/s00425-0060343-8

Lino, B., Chagolla, A., and González de la Vara, L. E. (2016). Membrane proteins involved in transport, vesicle traffic and $\mathrm{Ca}^{2+}$ signaling increase in beetroots grown in saline soils. Planta 244, 87-101. doi: 10.1007/s00425-016-2488-4

Lord, C. E., and Gunawardena, A. H. (2012). Programmed cell death in C. elegans, mammals and plants. Eur. J. Cell Biol. 91, 603-613. doi: 10.1016/j.ejcb.2012.02. 002

Martínez-Fábregas, J., Díaz-Moreno, I., González-Arzola, K., Janocha, S., Navarro, J. A., Hervás, M., et al. (2013). New Arabidopsis thaliana cytochrome c partners: a look into the elusive role of cytochrome $\mathrm{c}$ in programmed cell death in plants. Mol. Cell Proteom. 12, 3666-3676. doi: 10.1074/mcp.M113.030692

Ni, X. L., Gui, M. Y., Tan, L. L., Zhu, Q., Liu, W. Z., and Li, C. X. (2019). Programmed cell death and aerenchyma formation in water-logged sunflower stems and its promotion by ethylene and ROS. Front. Plant Sci. 9:1928. doi: 10.3389/fpls.2018.01928

Pedersen, P. L. (2008). Voltage dependent anion channels (VDACs): a brief introduction with a focus on the outer mitochondrial compartment's roles together with hexokinase-2 in the "Warburg effect" in cancer. J. Bioenerg. Biomembr. 40, 123-126. doi: 10.1007/s10863-008-9165-7

Pertl-Obermeyer, H., Schulze, W. X., and Obermeyer, G. (2014). In vivo crosslinking combined with mass spectrometry analysis reveals receptor-like kinases and $\mathrm{Ca}^{2+}$ signalling proteins as putative interaction partners of pollen plasma membrane $\mathrm{H}^{+}$ATPases. J. Proteomics 108, 17-29. doi: 10.1016/j.jprot.2014.05. 001

Petraglia, T., and Poole, R. J. (1980). Effect of anoxia on ATP levels and ion transport rates in red beet. Plant Physiol. 65, 973-974. doi: 10.1104/pp.65.5.973

Petrov, V., Hille, J., Mueller-Roeber, B., and Gechev, T. S. (2015). ROS-mediated abiotic stress-induced programmed cell death in plants. Front. Plant Sci. 6:69. doi: 10.3389/fpls.2015.00069

Qi, Y. H., Mao, F. F., Zhou, Z. Q., Liu, D. C., Min-Yu, Deng, X. Y., et al. (2018). The release of cytochrome $c$ and the regulation of the programmed cell death progress in the endosperm of winter wheat (Triticum aestivum L.) under waterlogging. Protoplasma 255, 1651-1665. doi: 10.1007/s00709-018-12 56-7

Reape, T. J., and McCabe, P. F. (2008). Apoptotic-like programmed cell death in plants. New Phytologist 180, 13-26. doi: 10.1111/j.1469-8137.2008.02549.x

Rikhvanov, E. G., Gamburg, K. Z., Varakina, N. N., Rusaleva, T. M., Fedoseeva, I. V., Tauson, E. L., et al. (2007). Nuclear-mitochondrial cross-talk during heat shock in Arabidopsis cell culture. Plant J. 52, 763-778. doi: 10.1111/j.1365313X.2007.03275. X

Rodríguez Saavedra, C., Morgado Martínez, L. E., Burgos Palacios, A., King Díaz, B., López Coria, M., and Sánchez Nieto, S. (2021). Moonlighting proteins: the case of the hexokinases. Front. Mol. Biosci. 8:701975. doi: 10.3389/fmolb.2021. 701975

Schägger, H., and von Jagow, G. (1987). Tricine-sodium dodecyl sulfate polyacrylamide gelelectrophoresis for the separation of proteins in the range from 1 to $100 \mathrm{kDa}$. Anal Biochem. 166, 368-379. doi: 10.1016/0003-2697(87) 90587-2

Senkler, J., Senkler, M., Eubel, H., Hildebrandt, T., Lengwenus, C., Schertl, P., et al. (2017). The mitochondrial complexome of Arabidopsis thaliana. Plant 89, 1079-1092. doi: 10.1111/tpj.13448

Shevchenko, A., Wilm, M., Vorm, O., and Mann, M. (1996). Mass spectrometric sequencing of proteins from silver-stained polyacrylamide gels. Anal Chem. 68, 850-858. doi: 10.1021/ac950914h

Shoshan-Barmatz, V., Ben-Hail, D., Admoni, L., Krelin, Y., and Tripathi, S. S. (2015). The mitochondrial voltage-dependent anion channel 1 in tumor cells. Biochim. Biophys. Acta 1848, 2547-2575. doi: 10.1016/j.bbamem.2014.10.040

Shoshan-Barmatz, V., Keinan, N., Abu-Hamad, S., Tyomkin, D., and Aram, L. (2010). Apoptosis is regulated by the VDAC1 N-terminal region and by VDAC oligomerization: release of cytochrome c, AIF and Smac/Diablo. Biochim. Biophys. Acta - Bioenerg. 1797, 1281-1291. doi: 10.1016/j.bbabio.2010.03.003
Shoshan-Barmatz, V., Keinan, N., and Zaid, H. (2008). Uncovering the role of VDAC in the regulation of cell life and death. J. Bioenerg. Biomembr. 40, 183-191. doi: 10.1007/s10863-008-9147-9

Shoshan-Barmatz, V., Krelin, Y., and Shteinfer-Kuzmine, A. (2018). VDAC1 functions in $\mathrm{Ca}^{2+}$ homeostasis and cell life and death in health and disease. Cell Calcium 69, 81-100. doi: 10.1016/j.ceca.2017.06.007

Sun, Y. L., Zhao, Y., Hong, X., and Zhai, Z. H. (1999). Cytochrome c release and caspase activation during menadione-induced apoptosis in plants. FEBS Lett. 462, 317-321. doi: 10.1016/s0014-5793(99)01539-2

Swidzinski, J. A., Leaver, C. J., and Sweetlove, L. J. (2004). A proteomic analysis of plant programmed cell death. Phytochemistry 65, 1829-1838. doi: 10.1016/j. phytochem.2004.04.020

Takahashi, Y., and Tateda, C. (2013). The functions of voltage-dependent anion channels in plants. Apoptosis 18, 917-924. doi: 10.1007/s10495-013-0845-3

Vacca, R. A., de Pinto, M. C., Valenti, D., Passarella, S., Marra, E., and De Gara, L. (2004). Production of reactive oxygen species, alteration of cytosolic ascorbate peroxidase, and impairment of mitochondrial metabolism are early events in heat shock-induced programmed cell death in tobacco bright-yellow 2 cells. Plant Physiol. 134, 1100-1112. doi: 10.1104/pp.103.035956

Van Aken, O., and Van Breusegem, F. (2015). Licensed to kill: mitochondria, chloroplasts, and cell death. Trends Plant Sci. 20, 754-766. doi: 10.1016/j. tplants.2015.08.002

Vartapetian, B. B., Andreeva, I. N., Generozova, I. P., Polyakova, L. I., Maslova, I. P., Dolgikh, Y. I., et al. (2003). Functional electron microscopy in studies of plant response and adaptation to anaerobic stress. Ann. Bot. 91, 155-172. doi: $10.1093 / \mathrm{aob} / \mathrm{mcf} 244$

Voesenek, L. A. C. J., and Bailey-Serres, J. (2015). Flood adaptive traits and processes: an overview. New Phytol. 206, 57-73. doi: 10.1111/nph.13209

Wang, J., Li, X., Liu, Y., and Zha, X. (2010). Salt stress induces programmed cell death in Thellungiella halophila suspension-cultured cells. J. Plant Physiol. 67, 1145-1151. doi: 10.1016/j.jplph.2010.03.008

Wittig, I., Beckhaus, T., Wumaier, Z., Karas, M., and Schägger, H. (2010). Mass estimation of native proteins by blue native electrophoresis. Principles and practical hints. Mol. Cell Proteom. 9, 2149-2161. doi: 10.1074/mcp.M900526MCP200

Wittig, I., Braun, H. P., and Schägger, H. (2006). Blue native PAGE. Nat. Protoc. 1, 418-428. doi: 10.1038/nprot.2006.62

Zalk, R., Israelson, A., Garty, E. S., Azoulay-Zohar, H., and Shoshan-Barmatz, V. (2005). Oligomeric states of the voltage-dependent anion channel and cytochrome c release from mitochondria. Biochem. J. 386, 73-83. doi: 10.1042/ BJ20041356

Zhang, Q. F., Li, J., Bi, F. C., Liu, Z., and Yao, N. (2020). Ceramide-induced cell death depends on calcium and caspase-like activity in rice. Front. Plant Sci. 11:145. doi: 10.3389/fpls.2020.00145

Conflict of Interest: The authors declare that the research was conducted in the absence of any commercial or financial relationships that could be construed as a potential conflict of interest.

Publisher's Note: All claims expressed in this article are solely those of the authors and do not necessarily represent those of their affiliated organizations, or those of the publisher, the editors and the reviewers. Any product that may be evaluated in this article, or claim that may be made by its manufacturer, is not guaranteed or endorsed by the publisher.

Copyright (๐ 2021 Rojas-Méndez, Sánchez Segura, Chagolla, Lino and González de la Vara. This is an open-access article distributed under the terms of the Creative Commons Attribution License (CC BY). The use, distribution or reproduction in other forums is permitted, provided the original author(s) and the copyright owner $(s)$ are credited and that the original publication in this journal is cited, in accordance with accepted academic practice. No use, distribution or reproduction is permitted which does not comply with these terms. 